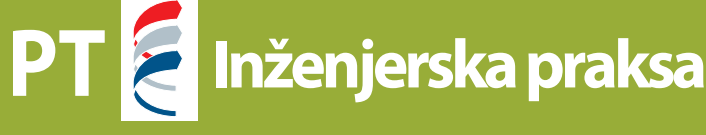

G. JANKES, M. KOSTIĆ, M. SALETA,

N. PETKOVIĆ, M. RADOSAVLJEVIĆ

https://doi.org/10.24094/ptc.017.29.1.40

\section{Kogeneracija u industriji korišćenjem gasnih motora}

$\mathrm{P}$ rimena kogeneracije, ili kombinovane proizvodnje toplotne i električne energije (CHP) je jedan od načina za povećanje energetske efikasnosti snabdevanja energijom industrijskih preduzeća. Kako se realizuje smanjenje potrošnje primarne energije uz zadovoljenje jednakih potreba kod finalne potrošnje pokazano je na slici 1.
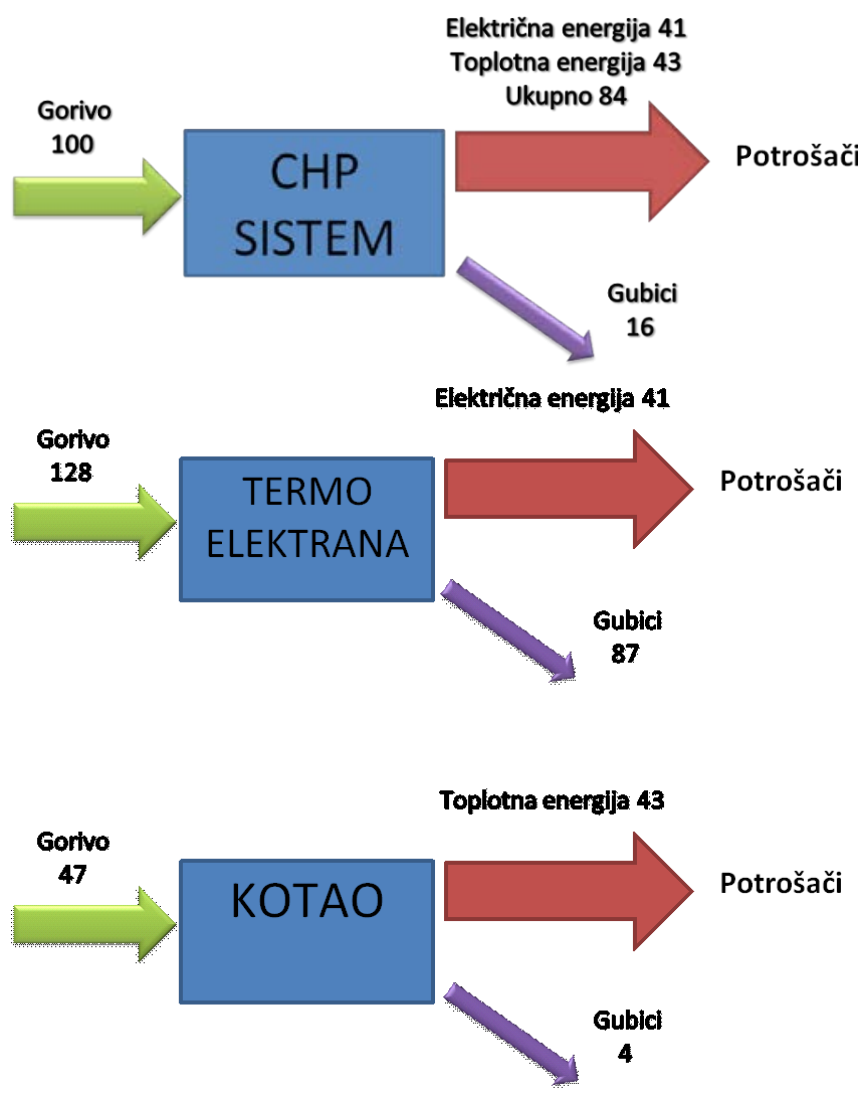

Slika 1: Poređenje snabdevanja energijom iz CHP postrojenjasa gasnim motorom i iz odvojene proizvodnje toplotne i električne energije

Tu je dato poređenje snabdevanja nekog industrjiskog preduzeća iz fabričkog CHP postrojenja sa gasnom motorom $\mathrm{i}$ iz odvojene proizvodnje električne i toplotne energije (fabrička kotlarnica + elektrana I el. distributivna mreža). Veća energetske efikasnosti snabdevanja energijom iz CHP sistema je evidentna, jer se za jednake potrebe konzuma utroši značajno manje manje goriva (100:175 za primer na sl. 1). Problem je što se u samom industriskom preduzeću utroši više goriva kod primene ovih sistema nego kod snabdevanja energijom iz fabričke kotlarnice i elektro distributivne mreže (100:48 energetskih jedinica za primer na sl. 1). U uslovima niske cene električne energije, ili visoke cene goriva i nedovoljnog iskorišćenja raspoložive toplotne energije iz CHP postrojenja, postavlja se pitanje ekonomske efikasnosti ovih sistema.

Zato su dobra analiza potrošnje različitih vidova energije i postojećeg energetskog sistema od presudnog značaja za dobar izbor snage i načina rada CHP postrojenja. U praksi je bilo slučajeva da zbog neadekvatnog izbora nabavljeno CHP postrojenje stoji jer nema ekonomskog opravdanja za njegov pogon.

U radu su date osnove za analizu rada CHP postrojenja sa gasnim motorom i prikazan je uticaj karakteristika postrojenja na troškove energije.

\section{Način sprezanja kogenerativnih postrojenja sa potrošačima energije $u$ industriji}

Kod kogeneracije ili CHP postrojenja sa korišćenjem gasnih motora gasni motor sa unutrašnjim sagorevanjem spreže se sa generatorom za proizvodnju električne energije, a otpadna toplota motora koristi se za proizvodnju toplotne energije (tople vode, ili pare). Šeme sprezanja motora sa potrošačima toplotne energije pokazane su na slikama 2. i 3. Na sl. 2 pokazano je CHP postrojenje sa proizvodnjom tople vode i pare. Tu se topla voda šalje potrošačima preko izmenjivača toplote koji je uključen u krug hlađenja motora i izlazne temperature oko $80^{\circ} \mathrm{C}$, a para se proizvodi korišćenjem otpadne toplote dimnih gasova koji imaju temperature na izlazu iz motora $450-480{ }^{\circ} \mathrm{C}$.

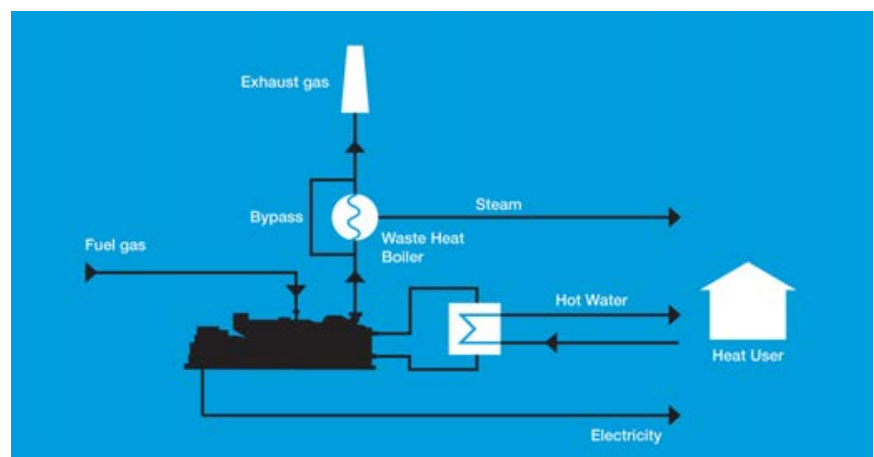

Legenda: Fuel gas - gasno gorivo; Exhaust gas - izduvni gas; Bypass obilazni vod; Steam - para; Waste heat boiler -kotao za otpadnu toplotu; Hot water - topla voda; Electricity - električna energija; Heat User Potrošač toplotne enegije

Slika 2: Kogeneracija sa proizvodnjom tople vode i pare/1/ 


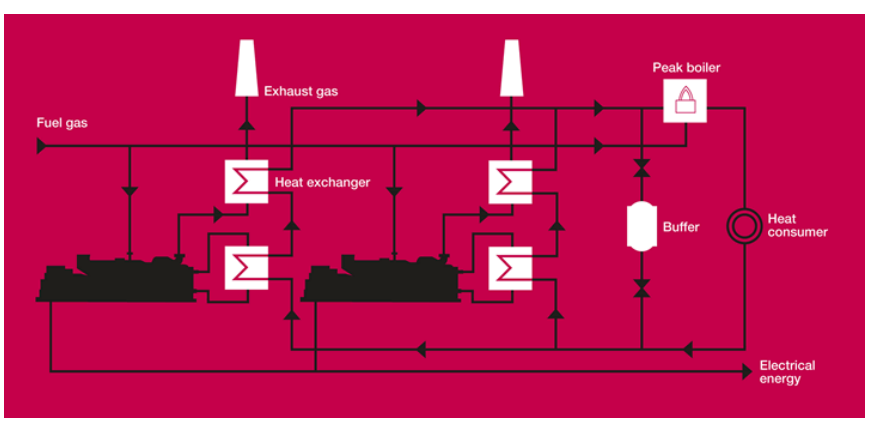

Legenda: Fuel gas - gasno gorivo; Exhaust gas - izduvni gas; Heat excanger - izmenjivač toplote; Buffer - akumulator toplote; Peak boiler - vršni kotao; Electrical energy - električna energija; Heat consumer konzum toplotne energije

Slika 3: Kogeneracija sa dva motora, vršnim kotlom i akumulatorom toplote za proizvodnju električne energije i tople vode /1/

Ukoliko je potrebna topla voda viših temperatura, umesto kotla utilizatora za proizvodnju pare, postavlja se drugi izmenjivač toplote (dimi gasovi-voda), pa se rashladna tečnost na izlazu iz motora prvo dodatno zagreva u tom izmenjivaču na potrebnu temperature, a zatim se preko posebnog izmenjivača zagreva topla voda $\left(90 / 70{ }^{\circ} \mathrm{C}\right.$, ili $100 / 70{ }^{\circ} \mathrm{C}$ ) koja se šalje potrošačima.

To je pokazano na sl. 3. gde CHP postrojenje sa dva motora uključuje i vršni kotao za dogrevanje vode i bafer za akumulaciju toplote, ukoliko su potrebe konzuma promenljive $\mathrm{u}$ toku dana kada su potrebe konzuma manje od toplote koju daju motori, bafer akumuliše toplotu, a u drugom periodu se bafer koristi kao dodatni izvor toplote.

CHP postrojenje može da prati potrebu za električnom energijom ("electricity tracking mode"), a toplotna energija je nusproizvod. Na ovaj način se minimizira količina električne energije koja se preuzima iz mreže. Ako je potreba za toplotnom energijom veća od proizvedene, kotao se uključuje da dopuni onu količinu toplotne energije koja nedostaje. Ako je potreba konzuma manja od trenutno proizvedene u CHP, deo toplotne energije se baca preko hladnjaka CHP u atmosferu. Ovo je nepovoljno sa stanovišta efikasnosti CHP postrojenja i da bi se minimizirala toplotna energija koja se baca u atmosferu, može se koristiti akumulator toplote u kome se akumulira toplotna energija u doba niskih potreba za toplotom (obično noću), a akumulisana toplota se isporučuje potrošačima u doba kada su potrebe za toplotom tehnoloških potrošača velike (obično prva smena).

Obrnuto, ako se prate potrebe za toplotnom energijom ("heat tracking mode"), ili je imperativ maksimalna efikasnost postrojenja (bez bacanja viška toplote), proizvodi se ona količina elektrčne energije koja odgovara potrebama u toplotnoj energiji. Ako je potreba konzuma toplotne energije veća nego proizvodnja na maksimalnoj snazi motora, uključuje se kotao radi dopune.

Proizvedena električna energija pokriva potrebe konzuma električne energije i ako su one manje od proizvodnje, deo električne energije se predaje distributivnoj mreži. Ukoliko su potrebe konzuma električne energije veće od proizvodnje CHP postrojenja, manjak se dopunjuje iz mreže.

Moguć je i stalan rad motora na maksimalnoj snazi bez obzira na potrebe u toplotnoj energiji. To se koristi u slučaju da je, ili cena električne energije koju plaća preduzeće toliko visoka da kompenzuje cenu goriva, ili ako postoji povoljna cena koju preduzeće dobija za isporučenu električnu energiju u odnosu na cenu goriva. Ako se povoljna cena ostvaruje preko povlašćene tarife ("feed'in" tarifa), onda se obično mora ispunjavati i uslov da ukupni godišnji stepen korisnosti mora da bude veći od propisanog za dobijanje povlašćene tarife. U tom slučaju se CHP postrojenje može kombinovati sa akumulatorom toplote koji se koristi u periodima godine kada postoji nizak toplotni konzum.

Prema tome kako se CHP povezuje sa distributivnom mrežom električne energije, mogu se razlikovati sledeće varijante rada postrojenja: a. ostrvski rad, b. kombinuje se pokriće sopstvenih potreba u električnoj energiji i isporuka viška u distributivnu mrežu, u slučaju da je konzum manji od proizvodnje CHP, i obrnuto, rad CHP maksimalnom snagom i preuzimanje manjka iz mreže, u slučaju visokih potreba konzuma, c. sva proizvedena električna energija se predaje distributivnoj mreži, a sopstvene porebe se namiruju preko posebog trafoa i mernog mesta iz mreže, što se koristi kada se preduzeću plaća povlašćena tarifa za isporučenu električnu energiju.

U slučaju da se nije realizovala povlašćena tarifa za isporučenu električnu energiju, tada je imperativ da se maksimalno iskoristi toplotna energija CHP postrojenja, jer postoje velike opasnosti da CHP ne radi ekonomično, odnosno da nije dobro odabrana snaga postrojenja. To zavisi od cena goriva ilektrične energije koju plaća preduzeće.

\section{Definisanje osnovnih parametara CHP postrojenja}

Ako je definisana električna snaga motora i označi se sa Pe $(\mathrm{kW})$, proizvođač motora na osnovu ispitivanja definiše električni i toplotni stepen korisnosti ( $\eta$ e i $\eta t$ ). Sa promenom opterećenja motora ove vrednosti se menjaju, s tim što opada $\eta$ e, a raste $\eta t$. Primer promene stepena korisnosti sa promenom snage CHP postrojenja sa gasnim motorom dat je u tabeli $1 / 2 /$.

Tabela 1. Karakteristike CHP postrojenja električne snage $1000 \mathrm{~kW} / 2 /$

\begin{tabular}{|l|c|c|c|c|}
\hline \multicolumn{1}{|c|}{ Opterećenje } & $\mathbf{1 0 0}$ & $\mathbf{7 5}$ & $\mathbf{5 0}$ & $\%$ \\
\hline Električna snaga & 1000 & 750 & 500 & $\mathrm{~kW}$ \\
\hline Toplotna snaga & 1027 & 810 & 597 & $\mathrm{~kW}$ \\
\hline Energija uneta gorivom & 2427 & 1871 & 1325 & $\mathrm{kWh} / \mathrm{h}$ \\
\hline $\begin{array}{l}\text { Temperatura izduvnih } \\
\text { gasova na izlazu iz motora }\end{array}$ & 458 & 477 & 496 & ${ }^{\circ} \mathrm{C}$ \\
\hline Električni stepen korisnosti & 41,2 & 40,1 & 37,7 & - \\
\hline Toplotni stepen korisnosti & 42,3 & 43,3 & 45,0 & - \\
\hline Ukupni stepen korisnosti & 83,5 & 83,4 & 82,7 & - \\
\hline
\end{tabular}

Ukupna energija uneta gorivom i raspoloživa toplotna energija računaju se na osnovu električne snage motora:

$P_{u}=P_{e} / \eta_{e}, P_{t}=P_{e} \cdot \eta_{t} / \eta_{e}$ ili $P_{t}=P_{u} \cdot \eta_{t}$

Ukupni stepen korisnosti CHP postrojenja definiše se kao: 


$$
\eta=\left(P_{e}+P_{t}\right) / P_{u}
$$

$\mathrm{Na}$ osnovu ovih izraza i poznate toplotne moći gasa $\left(\mathrm{H}_{\mathrm{d}}, \mathrm{kJ} / \mathrm{m}^{3}\right.$, ili $\mathrm{kWh} / \mathrm{m}^{3}$ ) izračunava se potrebna količina goriva:

$$
\begin{aligned}
& \mathrm{B}=3600 \cdot \mathrm{P}_{\mathrm{u}} / \mathrm{H}_{\mathrm{d}} \text { ako je toplotna moć izražena } \mathrm{u} \mathrm{kJ} / \mathrm{m}^{3} \text {, ili } \\
& \mathrm{B}=\mathrm{P}_{\mathrm{u}} / \mathrm{H}_{\mathrm{d}} \text { ako je toplotna moć izražena } \mathrm{u} \mathrm{kWh} / \mathrm{m}^{3}
\end{aligned}
$$

Na osnovu podataka proizvođača motora, za kogenerator nominalne električne snage $1000 \mathrm{~kW}$ u tabeli 1 prikazane su vrednosti električne, toplotne i ukupne snage motora, stepena korisnosti i izlaznih temperatura izduvnih gasova za različita opterećenja motora.

$\mathrm{Na}$ osnovu poznatih temperature izduvnih gasova i zadatih temperatura rashladne tečnosti na ulazu i izlazu iz motora određuju se količine otpadne toplote i snage izmenjivača toplote.

Količina toplote dimnih gasova se računa prema sledećoj formuli:

$$
Q_{g}=\frac{V_{R W} \cdot B}{3600} \cdot\left[\sum_{\substack{i \\ r_{p i}}}^{t_{i z}} \cdot t_{i z}-\sum r_{i} c_{p i}^{t_{u l}} \cdot t_{u l}\right]
$$

gde je:

$\mathrm{V}_{\mathrm{RW}}-\mathrm{m}^{3}{ }_{\mathrm{N}} / \mathrm{m}^{3}{ }_{\mathrm{G}}$ - produkata sagorevanja - izduvnih gasova po $\mathrm{m}^{3}{ }_{\mathrm{N}}$ goriva za zadati sastav goriva i koeficijent viška vazduha; $\lambda=1,6$ je vrednost viška vazduha s kojom gasni motor u praksi radi.

$\mathrm{B}-\mathrm{m}^{3}{ }_{\mathrm{N}} \mathrm{h}$ - potrošnja goriva,

$\mathrm{r}_{\mathrm{i}}-\mathrm{r}_{\mathrm{CO} 2}, \mathrm{r}_{\mathrm{H} 2 \mathrm{O}}, \mathrm{r}_{\mathrm{N} 2}, \mathrm{r}_{\mathrm{O} 2}-$ udeli komponenti u dimnim gasovima prema proračunu sagorevanja

$\mathrm{t}_{\mathrm{iz}} \mathrm{it}_{\mathrm{ul}}$ - temperature izduvnih gasova na izlazu i ulazu u izmenjivač toplote za korišćenje otpadne toplote izduvnih gasova,

$c_{p i}^{t_{i}} c_{p}$-srednji specifični toplotni kapacitet komponenti za temperature $\mathrm{t}_{\mathrm{iz}} \mathrm{i} \mathrm{t}_{\mathrm{ul}}\left(180^{\circ} \mathrm{C} \mathrm{i} 458^{\circ} \mathrm{C}\right.$ su vrednosti temperatura prema podacima proizvođača opreme $/ 2 /$.

Količina toplote koja se dobija hlađenjem motora određuje se prema izrazu:

$$
Q_{m}=\frac{\dot{m}_{V}}{3600} \cdot \rho \cdot c_{p} \cdot\left(t_{i z}-t_{u l}\right)
$$

gde je:

$\mathrm{m}_{\mathrm{v}}-\mathrm{m}^{3} / \mathrm{h}-$ protok rashladne tečnosti,

$c_{p}$ i $\rho-$ specifični toplotni kapacitet i gustina rashladne tečnosti (srednje vrednosti za temperature na izlazu i ulazu),

$\mathrm{t}_{\mathrm{iz}} \mathrm{i}_{\mathrm{ul}}$ - temperature rashladne tečnosti na izlazu i ulazu u motor.

$\mathrm{Q}_{\mathrm{g}}$ definisano preko otpadne toplote dimnih gasova mora da bude jednako

$$
Q_{V}=\frac{\dot{m}_{V}}{3600} \cdot \rho \cdot c_{p} \cdot\left(t_{i z 1}-t_{u l 1}\right)
$$

gde su:

$\mathrm{t}_{\mathrm{iz}}=\mathrm{t}_{\mathrm{ul1}}$ (temperature rashladne tečnosti na izlazu iz motora jednaka je temperaturi na ulazu u izmenjivač toplote dimnih gasova)

$\mathrm{t}_{\mathrm{izl}}$ - temperature rashladne tečnosti na izlazu iz izmenjivača toplote dimnih gasova

Navedene tri jednačine koriste se za dimenzionisanje izmenjivača toplote I određuju temperature i protok rashladne tečnosti.

\section{Faktori koji utiču na isplativost rada CHP postrojenja}

U praksi u jednom industrijskom pogonu snaga CHP postrojenja se bira prema dijagramima godišnjeg električnog i toplotnog opterećenja i to tako da CHP postrojenje pokriva bazno opterećenje, a dopunska količina energije se obezbeđuje iz drugih izvora (kotao, distributivna mreža).

Pri tome se mora voditi računa da ostatak toplotnog opterećenja koji se ne pokriva iz CHP postrojenja bude u granicama od tehničkog minimum do maksimalne toplotne snage kotla, ili obrnuto, ako se računa na postojeći kotao, snaga CHP postrojenja treba da bude u skladu sa toplotnom snagom kotla. Izuzetno, od ovog se mora odstupiti kod tehnoloških procesa koji ne smeju da ostanu bez napajanja električnom energijom. Pored toga, veoma je značajno da se snaga postrojenja bira u skladu sa dnevnim, nedeljnim i mesečnim promenama opterećenja.

Koliko je važan pravilan izbor snage postrojenja, ali i način na koji se postrojenje prilagodjava u radu trenutnim potrebama konzuma pokazaće se na primeru CHP postrojenja sa gasnim motorom električne snage 1000 kW. Pretpostavimo da je konzum električne energije uvek veći od snage CHP postrojenja i da ono moze uvek da radi punom snagom.

Karakteristike CHP postrojenja za slučaj da postrojenje prati električni konzum i radi punom snagom ("electricity tracking mode") uz zadovoljenje različitih potreba toplotnog konzuma dato je u tabeli 2, a za slučaj da postrojenje menja snagu usklađujući se sa potrebama toplotnog konzuma u tabeli 3. Ovde je pretpostavljena vred-

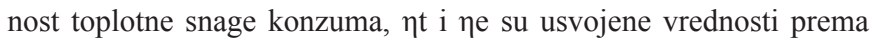
podacima proizvođača CHP postrojenja, a ostale veličine su računate prema gore navedenim jednačinama.

Tabela 2. Karakteristike CHP postrojenja $1000 \mathrm{kWe}$ za slučaj da postrojenje prati električni konzum ("electricity tracking")

\begin{tabular}{|c|c|c|c|c|c|c|}
\hline $\mathbf{P e}$ & $\mathbf{P t}$ & $\boldsymbol{\eta}_{\mathbf{e}}$ & $\boldsymbol{\eta}_{\mathbf{t}}$ & $\mathbf{B}$ & $\mathbf{P u}$ & $\boldsymbol{\eta}$ \\
\hline 1000 & 1024,1 & 0,415 & 0,425 & 256,1 & 2409,6 & 0,8400 \\
\hline 1000 & 800 & 0,415 & 0,425 & 256,1 & 2409,6 & 0,7470 \\
\hline 1000 & 600 & 0,415 & 0,425 & 256,1 & 2409,6 & 0,6640 \\
\hline 1000 & 400 & 0,415 & 0,425 & 256,1 & 2409,6 & 0,5810 \\
\hline 1000 & 300 & 0,415 & 0,425 & 256,1 & 2409,6 & 0,5395 \\
\hline
\end{tabular}

Tabela 3. Karakteristike CHP postrojenja $1000 \mathrm{kWe}$ za slučaj da postrojenje menja snagu usklađujući se sa potrebama toplotnog konzuma ("heat tracking")

\begin{tabular}{|c|c|c|c|c|c|c|}
\hline $\mathbf{P e}$ & $\mathbf{P t}$ & $\mathbf{\eta}_{\mathbf{e}}$ & $\boldsymbol{\eta}_{\mathbf{t}}$ & $\mathbf{B}$ & $\mathbf{P u}$ & $\boldsymbol{\eta}$ \\
\hline 1000 & 1024,1 & 0,415 & 0,425 & 256,1 & 2409,6 & 0,8400 \\
\hline 781,2 & 800 & 0,405 & 0,428 & 198,6 & 1869,2 & 0,8459 \\
\hline 585,9 & 600 & 0,395 & 0,435 & 146,6 & 1379,3 & 0,8598 \\
\hline 390,6 & 400 & 0,39 & 0,44 & 96,6 & 909,1 & 0,8696 \\
\hline 292,6 & 300 & 0,38 & 0,445 & 71,6 & 674,2 & 0,8795 \\
\hline
\end{tabular}


U ovom slučaju, sem kada je potreba konzuma jednaka isporučenoj količini toplote CHP postrojenja na maksimaklnoj snazi (1024 kW), višak toplotne energije CHP postrojenja baca se preko hladnjaka $u$ atmosferu. Tada je ukupni stepen korisnosti $\eta$ uvek manji od stepena korisnosti na maksimalnoj snazi (za ovaj primer $\eta_{\max }=$ $0,84)$.

Troškovi za energiju, ne uključujući anuitete i troškove održavanja, za oba slučaja prikazani su tabeli 4, pri čemu su dati uporedno troškovi CHP postrojenja i odvojenog snabdevanja jednakom količinom energije iz kotlarnice I distributivne mreže. Troškovi su svedeni na $1 \mathrm{~h}$ i izračunavaju se na sledeći način:

$$
\begin{aligned}
& \mathrm{T}_{\mathrm{eCHP}}=\mathrm{T}_{\mathrm{gCHP}}=\mathrm{B} \cdot \mathrm{Cg} \\
& \mathrm{T}_{\mathrm{e}}=\mathrm{T}_{\mathrm{gkot}}+\mathrm{T}_{\mathrm{el}}=\mathrm{Cg} \cdot \mathrm{P}_{\mathrm{t}} /\left(\mathrm{H}_{\mathrm{d}} \cdot \eta_{\mathrm{k}}\right)+\mathrm{Pe} \cdot \mathrm{Ce}
\end{aligned}
$$

gde su:

$\mathrm{T}_{\text {eCHP }}, \mathrm{T}_{\mathrm{gCHP}}, \mathrm{T}_{\mathrm{e}}, \mathrm{T}_{\mathrm{gkot}}, \mathrm{T}_{\mathrm{el}}(\mathrm{EUR} / \mathrm{h})$ - troškovi energije za CHP, troškovi za gas koji potroši CHP, troškovi energije odvojenog snabdevanja toplotnom i električnom energijom, troškovi za gas koji potroši kotao za ekvivalentnu količinu toplotne energije, troškovi za ekvivalentnu utrošenu količinu električne energije iz mreže,

$\mathrm{Cg}$ i Ce (EUR/kWh) - cena gasa, odnosno električne energije,

$\eta_{\mathrm{k}}-$ stepen korisnosti kotla.

Za proračun prikazan u tabeli 4 usvojena je cena gasa od 0,35 Eur/ $\mathrm{m}^{3}$, a cena za $1 \mathrm{kWh}$ električne energije varirana je $(0,07$ i 0,09 Eur/kWh, kao cena koju preduzeće u Srbiji plaćaju uzimajući u obzir sve troškove za električnu energiju). Kod ovog primera nije uzeta u obzir sopstvena potrošnja CHP postrojenja, pa je za realne slučajeve vrednost za ๆe niža za 2-4\% od vrednosti prikazanih u ovom primeru.

Rezultati proračuna prikazani u tabeli 4 vezani su i za karakteristike postrojenja prikazane prethodno u tabelama 2 i 3 . U koloni razlika, u tabeli 4, data je razlika u troškovima za energiju između odvojenog snabdevanja električnom i toplotnom energijom (kotao+distributivna mreža) i CHP postrojenja. Vidi se da su pozitivni efekti primene CHP kod visokih toplotnih opterećenja I da oni rastu sa porastom cene električne energije i sa smanjenjem cena gasa. Takođe je uočljivo da su efekti veći za opterećenja koja su bliska nominalnim i kad CHP postrojenje menja snagu na taj način da se usklađuje se sa potrebama toplotnog konzuma (heat tracking).

U poslednjoj koloni (godišnje) vrednosti razlika su pomnoženi sa 6000 h/god (godišnji broj časova rada motora) da bi se dobila slika o visini godišnjih efekata, što je važno za procenu isplativosti investicija i u skladu stim i za odlučivanje o nominalnoj snazi postrojenja. Za realno postrojenje visina godišnje uštede se dobija prema godišnjem dijagramu opterećenja, ili na osnovu poznavanja vrednosti srednji dnevnih, ili srednji mesečnih časovnih toplotnih opterećenja I broja sati rada u tom periodu.

Pored detaljne analize potrošnje energije, dobro poznavanje ukupne cene električne energije za svako preduzeće posebno je značajno za odluku o primeni CHP postrojenja. Cene od 0,07 i 0,09 Eur/kWh odabrane su na osnovu poznavanja sadašnjih troškova za električnu energiju u industriji u Srbiji. Sada su vrednosti od 0,07 Eur/kWh bliže proseku, mada kod preduzeća sa izrazito visokim udelom angažovane snage ove vrednosti mogu da budu i više od 0,09 Eur/kWh. Realno je očekivati porast cene električne energije, jer je Srbija među zemljama sa najnižim cenana električne energije u Evropi, što bi uticalo na porast isplativosti primene CHP postrojenja.

Tabela 4. Poređenje troškova za energiju kod snabdevanja energijom iz CHP postrojenja u odnosu na troškove odvojenog snabdevanja električnom i toplotnom energijom

\begin{tabular}{|c|c|c|c|c|c|c|c|c|}
\hline & & & & & & & 0,09 & EUR/kWh \\
\hline $\mathrm{Pe}$ & Pt & $n$ & $\mathrm{Tg}=\mathrm{Tch} p$ & Tel & Tgkot & Te & razl & godišnje \\
\hline 1000 & 1024,1 & 0,84 & 89,63 & 90,00 & 41,40 & 131,40 & 41,78 & 250666,3 \\
\hline 781,2 & 800 & 0,8459 & 69,52 & 70,31 & 32,34 & 102,65 & 33,13 & 198759,1 \\
\hline 585,9 & 600 & 0,8598 & 51,30 & 52,73 & 24,26 & 76,99 & 25,68 & 154103,7 \\
\hline 390,6 & 400 & 0,8696 & 33,81 & 35,15 & 16,17 & 51,32 & 17,51 & 105067,8 \\
\hline 292,9 & 300 & 0,8795 & 25,07 & 26,36 & 12,13 & 32,49 & 13,42 & 80510,47 \\
\hline
\end{tabular}

\begin{tabular}{|c|c|c|c|c|c|c|c|c|}
\hline \multicolumn{9}{|c|}{ Heat tracking } \\
\hline Pe & Pt & $\boldsymbol{\eta}$ & Tg=Tchp & Tel & Tgkot & Te & razl & godišnje \\
\hline 1000 & 1024,1 & 0,84 & 89,63 & 70,00 & 41,40 & 111,40 & 21,78 & 130666,3 \\
\hline 781,2 & 800 & 0,8459 & 69,52 & 54,68 & 32,34 & 87,03 & 17,50 & 105018 \\
\hline 585,9 & 600 & 0,8598 & 51,30 & 41,01 & 24,26 & 65,27 & 13,97 & 83797,85 \\
\hline 390,6 & 400 & 0,8696 & 33,81 & 27,34 & 16,17 & 43,51 & 9,70 & 58197,17 \\
\hline 292,9 & 300 & 0,8795 & 25,07 & 20,51 & 12,13 & 32,63 & 7,56 & 45357,53 \\
\hline
\end{tabular}

\begin{tabular}{|c|c|c|c|c|c|c|c|c|}
\hline \multicolumn{7}{|c|}{ Electricity tracking } & \multirow{2}{*}{$\begin{array}{l}0,07 \\
\text { razl }\end{array}$} & \multirow{2}{*}{$\begin{array}{l}\text { EUR/kWh } \\
\text { godišnje }\end{array}$} \\
\hline $\mathrm{Pe}$ & Pt & $\eta$ & $\mathrm{Tg}=\mathrm{Tch} p$ & Tel & Tgkot & Te & & \\
\hline 1000 & 1024,1 & 0,84 & 89,63 & 70 & 41,40 & 111,40 & 21,78 & 130666,3 \\
\hline 1000 & 800 & 0,747 & 89,63 & 70 & 32,34 & 102,34 & 12,72 & 76306,69 \\
\hline 1000 & 600 & 0,664 & 89,63 & 70 & 24,26 & 94,26 & 4,63 & 27792,16 \\
\hline 1000 & 400 & 0,581 & 89,63 & 70 & 16,17 & 86,17 & $-3,45$ & $-20722,4$ \\
\hline 1000 & 300 & 0,5395 & 89,63 & 70 & 12,13 & 82,13 & $-7,5$ & $-44979,6$ \\
\hline
\end{tabular}

\begin{tabular}{|c|c|c|c|c|c|c|c|c|}
\hline & & & & & & & 0,09 & EUR/kWh \\
\hline $\mathrm{Pe}$ & Pt & $\eta$ & $\mathrm{Tg}=\mathrm{Tch} p$ & Tel & Tgkot & Te & razl & godišnje \\
\hline 1000 & 1024,1 & 0,84 & 89,63 & 90 & 41,40 & 131,4 & 41,78 & 250666,3 \\
\hline 1000 & 800 & 0,747 & 89,63 & 90 & 32,34 & 122,34 & 32,72 & 196306,7 \\
\hline 1000 & 600 & 0,664 & 89,63 & 90 & 24,26 & 114,26 & 24,63 & 147792,2 \\
\hline 1000 & 400 & 0,581 & 89,63 & 90 & 16,17 & 106,17 & 16,55 & 99277,63 \\
\hline 1000 & 300 & 0,5395 & 89,63 & 90 & 12,13 & 102,13 & 12,5 & 75020,37 \\
\hline
\end{tabular}

Za upotpunjavanje podataka neophodnih za procene isplativosti CHP postrojenja treba poznavati visinu investicija I troškove održavanja ovih postrojenja. Prema iskustvu autora, investicija se kreće od oko 800 EUR/kWe (smeštaj u postojeće objekte sa infra- 
strukturom) do 1100 Eur/kWe (za postrojenja kontejnerskog tipa). Troškovi održavanja se obično obračunavaju po broju sati rada motora i različiti su, zavisno od isporučioca opreme.

\section{Rad CHP postrojenja sa povlašćenom tarifom za isporučenu električnu energije}

Ako se očekuje dobijanje povlašćene tarife za prodaju isporučene električne energije $\mathrm{i}$ isporuka proizvedene električne energije u distributivnu mrežu, menja se izbor načina rada postrojenja i procena isplativosti postrojenja. U tom slučaju se maksimalna količina proizvedene električne energije predaje ED mreži, a sopstvene potrebe se podmiruju iz mreže. Važno je da se ostvari što je moguće veći broj sati rada na visokim opterećenjima CHP postrijenja, ali je pri tome ograničenje da se mora ostvariti ukupni godišnji stepen korisnosti CHP postrojenja veći od onog koje propisuje Uredba/3/. Po važećoj uredbi je to $75 \%$.

U tom slučaju se mogu odabrati dva moguća načina za rad postrojenja.

Prvi je rad sa akumulatorom toplote, kada postrojenje radi maksimalnom snagom i pušta se u rad za vreme punjenja akumulatora. Kada se akumulator napuni, postrojenje prekida rad i toplotni konzum se pokriva iz akumulatora.

Drugi način je da CHP postrojenje menja snagu usklađujući se sa potrebama toplotnog konzuma (heat tracking), pri čemu se, da bi postrojenje radilo sa maksimalnom proizvodnjom električne energije, postavlja uslov da ukupni stepen korisnosti bude uvek blizak minimalnoj vrednosti koju dozvoljava Uredba, naprimer:

$$
\begin{aligned}
& \left(P_{e}+P_{t}\right) / P_{u}=0,76 \\
& P e=P t \cdot \frac{0,76}{\eta t-1}
\end{aligned}
$$

U ovom slučaju se električna snaga definiše prema poznatoj (potrebnoj) toplotnoj snazi konzuma, a najniže vrednosti stepena korisnosti se biraju da bi se dobila veća električna snaga, odnosno veća količina isporučene električne energije. Ovaj uslov ( $\eta$ u približno jednako minimalnoj vrednosti koju propisuje Uredba) pretpostavlja da se deo toplotne energije koji je veći od potreba konzuma odvodi preko hladnjaka CHP postrojenja u atmosferu.

U slučaju rada CHP postrojenja sa akumulatorom toplote postrojenje radi uvek maksimalnom snagom. Za definisanje ukupne godišnje proizvodnje električne energije i načina vođenja postrojenja, potrebno je odrediti vreme punjenja akumulatora (CHP postrojenje je $\mathrm{u}$ radu, puni akumulator i istovremeno pokriva potrebe toplotnog konzuma) i vreme pražnjenja akumulatora (postrojenje ne radi, potrebe konzuma se pokrivaju iz akumulatora toplote).

Proračun vremena punjenja i pražnjenja akumulatora vrši se na osnovu toplotnog bilansa za period punjenja i za period pražnjenja akumulatora/4/.

1. Toplotni bilans akumulatora toplote za period punjenja akumulatora $\mathrm{i}$ vreme punjenja:

$$
\begin{aligned}
& \mathrm{Q}_{\mathrm{R}}=\left(\mathrm{P}_{\mathrm{tm}}-\mathrm{P}_{\text {kon }}\right) \cdot \tau_{1} \\
& \tau_{1}=\mathrm{Q}_{\mathrm{R}} /\left(\mathrm{P}_{\mathrm{tm}}-\mathrm{P}_{\text {kon }}\right)
\end{aligned}
$$

gde je

$\tau_{1}$ - vreme punjenja rezervoara za akumulaciju toplote $(\mathrm{h})$,

$\mathrm{Q}_{\mathrm{R}}$ - količina toplote $\mathrm{u}$ akumulatoru $(\mathrm{kJ})$,

$\mathrm{Q}_{\mathrm{R}}=\mathrm{V} \cdot \mathrm{c}_{\mathrm{p}} \cdot \rho \cdot \Delta \mathrm{t}(\mathrm{kJ})$,

$\mathrm{V}$ - zapremina rezervoara - akumulatora toplote $(180 \mathrm{~m} 3)$,

cp - specifični toplotni kapacitet za vodu 4,187 (J/kg•K),

$\rho$ - gustina vode $(\mathrm{kg} / \mathrm{m} 3)$,

$\Delta \mathrm{t}$ - razlika temperatura $-30^{\circ} \mathrm{C}\left(90^{\circ} \mathrm{C}-60^{\circ} \mathrm{C}\right)$ ili $30 \mathrm{~K}$,

$\mathrm{P}_{\mathrm{tm}}$ - maksimalna toplotna snaga kogeneracionog postrojenja:

$\mathrm{P}_{\mathrm{e}} \cdot \eta_{\mathrm{t}} / \eta_{\mathrm{e}}\left(\mathrm{kW}\right.$ ili KJ/s), $\mathrm{P}_{\mathrm{e}}$ - električna snaga generatora $(\mathrm{kW})$,

$\eta_{\mathrm{t}}-$ toplotni stepen korisnosti,

$\eta_{\mathrm{e}}-$ električni stepen korisnosti,

$\mathrm{P}_{\text {kon }}$ - toplotna snaga konzuma $(\mathrm{kW}$ ili $\mathrm{KJ} / \mathrm{s})$-proračunava se na osnovu izmerenih vrednosti, odnosno na osnovu Usvojene vrednosti potreba za toplotnom energijom po mesecima prema podacima dobijenih od Naručioca.

2. Toplotni bilans akumulatora toplote za period pražnjenja akumulatora i vreme pražnjenja

$\mathrm{Q}_{\mathrm{R}}=\mathrm{P}_{\mathrm{kon}} \cdot \tau_{2}$

$\tau_{2}=Q_{R} / P_{\text {kon }}$

Vreme ciklusa $(\mathrm{h})=\tau_{1}+\tau_{2}$

Broj ciklusa mesečno, $\mathrm{n}=\mathrm{H} /\left(\tau_{1}+\tau_{2}\right)$,

$\mathrm{H}$ - broj časova mesečno (h)

Broj sati rada $=\mathrm{n} \cdot \tau_{1}$

Mesečna proizvodnja električne energije

$\mathrm{Q}_{\mathrm{e}}=\mathrm{P}_{\mathrm{e}} \cdot \mathrm{n} \cdot \tau_{1}(\mathrm{kWh} / \mathrm{mes}), \mathrm{P}_{\mathrm{e}}=1000 \mathrm{~kW}$ (maksimalna električna snaga generatora)

Ukupna energija uneta gorivom $\mathrm{Q}_{\text {gor }}=\mathrm{Q}_{\mathrm{e}} / \eta_{\mathrm{e}}$

Q ukupno - Ukupna energija = zbir električne i toplotne energije

Ukupni godišnji stepen korisnosti $\eta=$ Qukupno / Qgor $\geq 75 \%$ (minimalna vrednost propisana Uredbom)

Kod rada sa akumulatorom toplote, ako je snaga CHP postrojenja odabrana tako da pokriva sve potrebe toplotnog konzuma i ukoliko se traži ispunjenje uslova za dobijanje povlašćene tarife za isporučenu električnu energiju, mogu se, zavisno od potreba konzuma, javiti tri režima rada postrojenja sa akumulatorom:

1. U vreme niskih potreba konzuma (letnji meseci) vreme punjenja akumulatora je kraće od vremena pražnjenja. Tada upravljački uređaj bira (koriguje) broj sati neprekidnog rada motora I u tim mesecima je odabrano vreme neprekidnog rada začajno je veći od vremena punjenja prema gore pokazanim bilansnim jednačinama. Dužina vremena rada motora za korigovano vreme rada odabrana je da se realizuje rad sa maksimalnom snagom u jednom ciklusu na dan. Pri radu generatora dopunjuje se akumulator, pokriju se toplotne potrebe konzuma, a višak toplotne energije do maksimalne toplotne snage se izbacuje preko vazdušnih hladnjaka u atmosferu. Ukupan broj sati rada u ovom režimu bira se tako da godišnji stepen korisnosti bude blizak, ali veći od 0,76 (Uredba dozvoljava veći od 75\%). 
2. U vreme visokih potreba toplotnog konzuma vreme punjenja prema gore pokazanim bilansnim jednačinama je veće od 24 $\mathrm{h}$ i motor može da radi kontinualno, isporučuje se potrebna količina energije konzumu, akumulator je napunjen, a višak energije se baca u atmosferu. Za izračunavanje ukupnog stepena korisnosti uzima se u obzir samo energija isporučena konzumu.

3. Kada je vreme punjenja akumulatora duže od vremena pražnjenja, ali manje od $24 \mathrm{~h}$, generator radi po ciklusima punjenja i pražnjenja akumulatora toplote izračunatim prema jednačinama energetskog bilansa.

Neophodni uslov za realizaciju ovakvog rada CHP postrojenja je da odgovarajući upravljački uređaj vodi rad postrojenja I definiše gore navedene režime rada.

Zavisno od maksimalne toplotne snage motora iz bilansnih jednačina se može definisati za koju toplotnu snagu konzuma su vremena punjenja i pražnjenja jednaka. Takođe se, zavisno od maksimalne toplotne snage motora i veličine akumulatora, iz bilansnih jednačina može definisati za koju toplotnu snagu konzuma je vreme punjenja akumulatora jednako $24 \mathrm{~h}$.

Gore navedene bilansne jednačine mogu se koristiti za proračun vremena punjenja i pražnjenja akumulatora i kod industrijskih postrojenja sa CHP postrojenjem gde postoje neravnomerne dnevne potrebe u toplotnoj energiji.

\section{Zaključak}

CHP postrojenje sa gasnim motorom je jedno od mogućih rešenja za kogeneraciju u industriji koje ima visoke vrednosti električnog i ukupnog stepena korisnosti, a električni stepen korisnosti se relativno malo menja sa promenom snage postrojenja. Neosporno je da je energetska efikasnost ovakvog postrojenja značajno viša nego kod snabdevanja nekog industrijskog konzuma električnom energijom iz mreže, a toplotnom iz fabričkog kottla. Problem kod procene isplativosti primene ovakvog postrojenja je što se u samom industriskom preduzeću utroši više goriva kod primene ovakvog postrojenja nego kod snabdevanja energijom iz fabričke kotlarnice i elektro distributivne mreže. Tada pariteti cena goriva i električne energije i nivo plasmana toplotne energije, kako je to u radu pokazano, određuju isplativost postrojenja. Pažljiva tehnička analiza konzuma i energetskog sistema i finansijska analiza odabranog slučaja moraju da predhode konačnoj odluci o nabavci i primeni CHP postrojenja. Zbog promašaja kojih je bilo u praksi, ovaj rad je imao za cilj da ukaže na osnovne probleme pri izboru snage i načina rada ovih postrojenja.

\section{Literatura}

[1] https://www.clarke-energy.com/gas-engines

[2] Podaci proizvođača Caterpillar, http://www.caterpillar.com/

[3] Uredba o uslovima i postupku sticanja statusa povlašćenog proizvođača električne energije, privremenog povlašćenog proizvođača i proizvođača električne energije iz obnovljivih izvora energije, Službeni glasnik RS, broj 56/2016

[4] Projektna dokumentacija CEEFOR

\section{Autori}

Goran JANKES

Inovacioni centar Mašinskog fakulteta Univerziteta u

Beogradu

Kraljice Marije 16, Beograd

Centar za energetsku efikasnost i održivi razvoj CEEFOR Beograd

Miloš KOSTIĆ

Centar za energetsku efikasnost i održivi razvoj CEEFOR Beograd

Miloš SALETA

Centar za energetsku efikasnost i održivi razvoj CEEFOR Beograd

\author{
Nikola PETKOVIĆ \\ Centar za energetsku efikasnost i održivi razvoj - \\ CEEFOR Beograd
}

\section{Marko RADOSAVLJEVIĆ \\ Centar za energetsku efikasnost i održivi razvoj - CEEFOR Beograd}

\section{Članski popust na izdanja SMEITS-a}

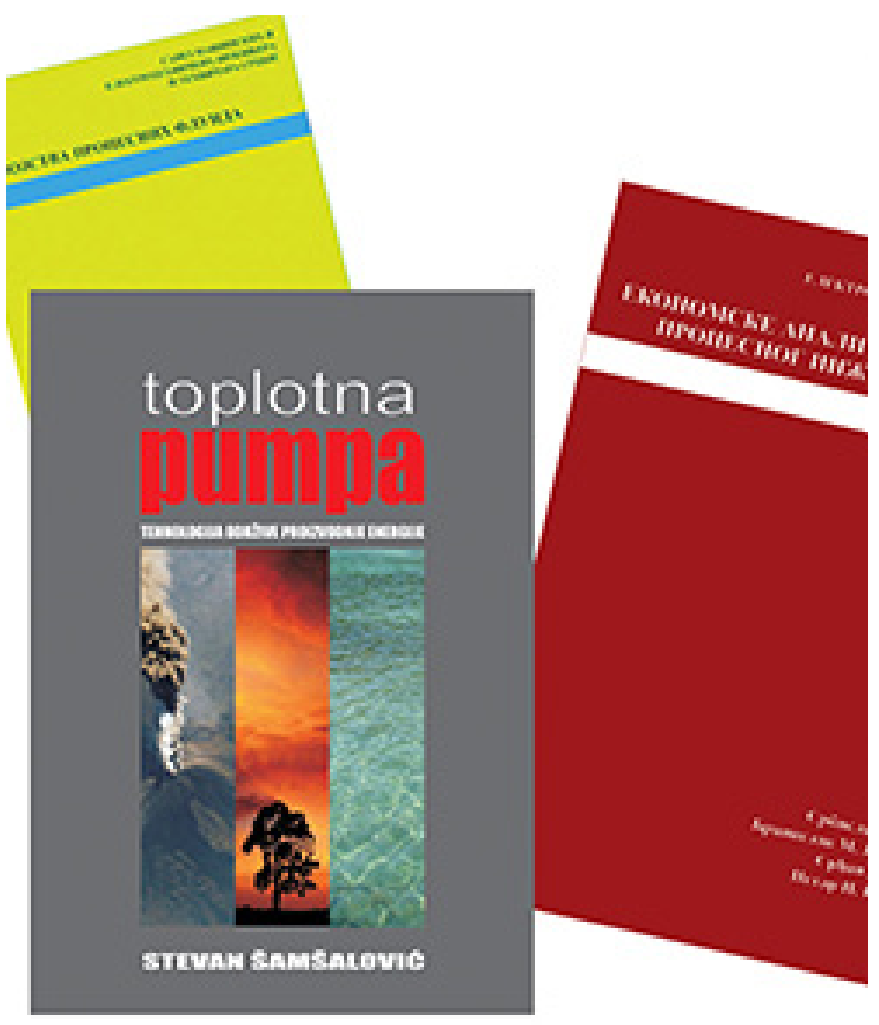

